MICHIGAN RETIREMENT AND DISABILITY RESEARCH CENTER UNIVERSITY OF MICHIGAN

Promoting research on retirement, disability, and Social Security policy

\title{
The Risk of High Out-of-Pocket Health Spending among Older Americans
}

Helen Levy

MRDRC WP 2020-409

UM20-09 


\title{
The Risk of High Out-of-Pocket Health Spending among Older Americans
}

\author{
Helen Levy \\ University of Michigan and NBER
}

September 2020

Michigan Retirement and Disability Research Center, University of Michigan, P.O. Box 1248. Ann Arbor, Ml 48104, mrdrc.isr.umich.edu, (734) 615-0422

\section{Acknowledgements}

The research reported herein was performed pursuant to a grant from the U.S. Social Security Administration (SSA) funded as part of the Retirement and Disability Research Consortium through the University of Michigan Retirement and Disability Research Center Award RDR18000002-02. The opinions and conclusions expressed are solely those of the author(s) and do not represent the opinions or policy of SSA or any agency of the federal government. Neither the United States government nor any agency thereof, nor any of their employees, makes any warranty, express or implied, or assumes any legal liability or responsibility for the accuracy, completeness, or usefulness of the contents of this report. Reference herein to any specific commercial product, process or service by trade name, trademark, manufacturer, or otherwise does not necessarily constitute or imply endorsement, recommendation or favoring by the United States government or any agency thereof.

\section{Regents of the University of Michigan}

Jordan B. Acker; Huntington Woods; Michael J. Behm, Grand Blanc; Mark J. Bernstein, Ann Arbor; Paul W. Brown, Ann Arbor; Shauna Ryder Diggs, Grosse Pointe; Denise llitch, Bingham Farms; Ron Weiser, Ann Arbor; Katherine E. White, Ann Arbor; Mark S. Schlissel, ex officio 


\title{
The Risk of High Out-of-Pocket Health Spending among Older Americans
}

\begin{abstract}
Traditional Medicare imposes significant cost-sharing on beneficiaries. Most but not all beneficiaries obtain supplemental insurance through Medigap, Medicare Advantage, Medicaid, or employer-sponsored retiree coverage, which may vary in how well they protect against the risk of high spending. This paper uses data from the Health and Retirement Study for the years 2002 through 2016 to document how supplemental coverage for Medicare beneficiaries 65 and older has changed over time, and to estimate the distribution of out-of-pocket spending for enrollees with different coverage types. I find that the shares of beneficiaries with employersponsored supplemental coverage or Medigap declined between 2002 and 2016, whereas the shares with Medicare Advantage or no supplemental coverage for doctor and hospital bills have increased. The majority of those with no supplemental coverage for doctor and hospital bills have Medicare Part D, which covers prescription drug expenses. I find that all supplemental coverage types are associated with lower observed dispersion in out-of-pocket medical care spending, measuring dispersion as the ratio of the 90th to the 50th percentile or the standard deviation. All supplemental insurance types are associated with a lower probability that out-ofpocket medical care spending exceeds $10 \%$ of household income, while all but Medicaid are associated with a significantly higher probability that total out-of-pocket health spending (that is, medical care plus health insurance premiums) exceeds this threshold. Thus, all supplemental insurance forms effectively function as insurance, translating uncertain medical costs into more predictable — although still potentially burdensome — premiums.
\end{abstract}

\section{Citation}

Levy, Helen. 2020. "The Risk of High Out-of-Pocket Health Spending among Older Americans." Ann Arbor, MI. University of Michigan Retirement and Disability Research Center (MRDRC) Working Paper; MRDRC WP 2020-409.

https://mrdrc.isr.umich.edu/publications/papers/pdf/wp409.pdf 


\section{Introduction}

High out-of-pocket health care costs are a significant threat to older Americans' financial security. Even with near-universal Medicare coverage beginning at age 65 , the median older household devotes $12 \%$ of its budget to medical care and health insurance, compared with less than 3\% for nonelderly households (Gruber and Levy 2009). Moreover, this spending is highly concentrated, with $5 \%$ of households responsible for half of out-of-pocket spending on medical care (DeNardi et al. 2016).

One reason older households are at risk of high spending is that traditional Medicare coverage leaves beneficiaries exposed to potentially very high levels of costsharing, with no cap on their total cost. To limit their risk exposure, most traditional Medicare enrollees obtain supplemental coverage to limit their exposure to risk through Medicaid, an employer-sponsored plan, or by buying a private Medigap plan, but $19 \%$ do not (Cubanski et al. 2018). Moreover, neither Medigap plans nor employersponsored retiree plans are required to cap enrollee out-of-pocket costs, unlike private plans for nonelderly individuals. While Medicare Advantage plans limit enrollee costsharing, the out-of-pocket cap is still very high - currently $\$ 6,700$ per individual. Thus, with the exception of those who have Medicaid in addition to Medicare, all Medicare enrollees are potentially at risk of quite high out-of-pocket spending.

Which households are at risk of high out-of-pocket health care spending and why? This work updates earlier research by Goldman and Zissimopoulos (2003), who found using 1998 data that those with Medigap had out-of-pocket spending that was as high as or higher than traditional Medicare enrollees with no supplemental coverage, while beneficiaries with supplemental employer or Medicare Advantage have somewhat 
lower spending. The health insurance landscape for Medicare beneficiaries has shifted in the past two decades. These changes include the implementation of Medicare Part $D$ in 2006, the shift to high-deductible plans in the under-65 health insurance market, and the ongoing erosion of employer-sponsored retiree coverage. All of these changes have the potential to affect older Americans' exposure to health spending risk.

In this paper, I analyze data on health insurance coverage and out-of-pocket health spending for Medicare beneficiaries 65 and older from the nationally representative Health and Retirement Study over the period 2002 through 2016. This analysis yields several interesting results. First, there have been substantial changes in the distribution of Medicare beneficiaries' supplemental coverage over time, in particular, declines in the share who have employer-sponsored coverage or Medigap as a supplement to Medicare, and an increase in the share with Medicare Advantage. On net, the fraction who have no supplemental coverage has dropped if Medicare Part D, which covers only prescription drugs, is counted as supplemental coverage: The fraction without supplemental coverage for doctor and hospital bills has increased, however. Second, while different supplemental coverage types place different levels of cost burden on beneficiaries, all of them reduce the observed dispersion of out-ofpocket spending (measured as ratio of $90^{\text {th }}$ percentile to $50^{\text {th }}$ percentile) compared to no supplemental coverage.

\section{Background on Medicare and supplemental coverage for}

\section{beneficiaries 65 and older}

Traditional Medicare coverage, consisting of Part A for hospital care and Part B for doctors' bills, exposes beneficiaries to out-of-pocket spending for two reasons. First, 
many services are simply not covered; for example, neither dental care not routine eye exams are covered by Medicare. Second, even for services that are covered, traditional Medicare requires both a deductible and cost-sharing with no cap on what the beneficiary may be asked to pay. ${ }^{1}$

Because of traditional Medicare's gaps, most beneficiaries have coverage from some other source. Possible sources of coverage include:

- Medicaid: Beneficiaries with very low income and assets qualify for Medicaid, which has minimal cost-sharing of any kind.

- Employer-sponsored coverage: Many beneficiaries have access to private coverage from their own or a spouse's current or former employer. Employers may contribute to premiums for this coverage, but they also may not. These plans may place a cap on enrollee liability for out-of-pocket costs, but there is no requirement that they do so.

- Medicare Advantage: Medicare beneficiaries also have the option of enrolling in a Medicare Advantage plan, sometimes called a Medicare HMO. In 2020, these plans are required to cap enrollee out-of-pocket spending at no more than $\$ 6,700$ for in-network services.

\footnotetext{
${ }^{1}$ The cost-sharing structure in traditional Medicare is complex. Under Part A, beneficiaries face a deductible of $\$ 1,408$ in 2020 per "benefit period," defined as beginning when the beneficiary is admitted to a hospital or skilled nursing facility and ending when the beneficiary has not received any inpatient or skilled nursing care in a 60-day period. Part $B$ has a deductible of $\$ 198$. Beyond the deductible, Part A has a nonlinear cost-sharing structure under which beneficiaries face no costs for 60 days, $\$ 352$ per day for days 60 through $90, \$ 704$ per day for days 91 and beyond up to a total of 60 "lifetime reserve days," after which beneficiaries bear all costs under Part A. Part B cost-sharing beyond the deductible is 20 percent with no cap. Sources: https://www.medicare.gov/your-medicare-costs/medicare-costs-at-a-glance and definition of benefit period.
} 
- Medigap: Private insurers also offer Medicare supplemental or "Medigap" plans, which are highly regulated and have standardized plan offerings. As of 2020 , only two Medigap plans had limits on out-of-pocket costs $(\$ 5,880$ for Plan $K$ and $\$ 2,940$ for Plan $L) .^{2}$

- Medicare Part D: Since 2006, Medicare beneficiaries with Parts A and B have had the option to enroll in Part D, which provides coverage for prescription drug expenses only. In 2021, Beneficiary out-of-pocket spending for Part $D$ plans is capped at $\$ 6,550$.

Even with supplemental coverage, not all plans will cover all services, such as dental care. Moreover, some out-of-pocket spending caps on covered services are quite high.

\section{Data and methods}

The analysis uses data from the 2002 through 2016 Health and Retirement Study (HRS), a longitudinal panel study of older Americans described in more detail elsewhere (Sonnega et al. 2014). Data are collected in even-numbered years, with sample sizes ranging from about 16,000 to 20,000 in each year. Table 1 shows sample sizes in the full HRS and in my analysis sample. I begin by restricting the sample to respondents 65 and older at the time of the interview who also have Medicare, yielding a sample size of about 10,000 in each year. The sample is further reduced by dropping a very small number of observations missing key covariates (age, health status, gender, education).

\footnotetext{
${ }^{2}$ https://www.medicare.gov/supplements-other-insurance/how-to-compare-medigap-policies
} 
The final sample consists of approximately 10,000 observations per year, with 19,464 unique individuals in the analysis sample during the period 2002 through 2016.

Health insurance measures are based on respondent reports of coverage at each survey wave. Respondents are asked whether or not they have Medicare, and only respondents 65 and older who report having Medicare (nearly all of those in this age range) are included in the analysis. Supplemental coverage measures are constructed from respondent reports of whether they are enrolled in a Medicare Advantage plan; whether they are covered by Medicaid; whether they are enrolled in a Medicare Part D plan; and whether they have any private insurance coverage. Respondents with private coverage are asked about the source of their coverage (own or spouse's current or former employer, directly from an insurance company, etc.). I use this to distinguish between employer-sponsored coverage and Medigap coverage. Some respondents report more than one coverage type in addition to Medicare. For example, a respondent might report having both employer-sponsored coverage and a Medicare Advantage plan. In practice, this overlap is quite rare. I define mutually exclusive categories of supplemental coverage using the following hierarchy to code coverage of individuals who report more than one source: Medicaid > employer coverage $>$ Medigap $>$ Medicare Advantage $>$ Part D. So, for example, a respondent reporting both employer coverage and an Medicare Advantage plan would be categorized as having employer coverage.

The HRS measures out-of-pocket health care spending in eight broad categories: hospitals (HOSP), outpatient surgery (OPS), doctor visits (DR), home health care (HHC), dental care (DENT), prescription drugs (DRUG), specialty care (SPEC), and 
nursing home care $(\mathrm{NHM}) .{ }^{3}$ I use cleaned and imputed values for all of these spending variables provided in the RAND HRS file. Variables in the RAND HRS file reflect the two-year recall period used in the HRS. I divide these numbers in half to get annual spending numbers, and inflate these values to 2016 dollars using the CPI-U. Therefore, the amounts reported in my analysis are for real, annual, out-of-pocket spending in 2016 dollars. I define out-of-pocket spending on medical care as the sum of these eight categories. Respondents are also asked about their premium spending for up to three private health insurance plans, Medicare Advantage coverage, and prescription drug coverage (private and Part D). I consider the sum of these amounts to be out-of-pocket spending on health insurance. Summing out-of-pocket spending on medical care and health insurance yields what I define as total out-of-pocket spending on health.

\section{Results, Part 1: Supplemental coverage trends over time; enrollee characteristics by coverage type; and beneficiary out-of-pocket}

\section{premium spending}

Figure 1 shows supplemental coverage of Medicare beneficiaries 65 and older from 2002 through 2016. In 2002, employers were the most common source of supplemental coverage, covering $42 \%$ of Medicare beneficiaries ages 65 and older. By 2016, this fraction had declined to $25 \%$. Medigap was the second most common source of supplemental coverage in 2002, covering $21 \%$ of beneficiaries. By 2016 , this had declined to $14 \%$. Together, these two sources of supplemental private coverage went

\footnotetext{
${ }^{3}$ In addition, beginning in 2010, a catch-all other category was added (OTHX); this category averages $\$ 140$. I ignore it for cross-wave consistency.
} 
from covering $63 \%$ of beneficiaries in 2002 to only $39 \%$ in 2016 . Medicare Advantage filled some of this gap, doubling its market share from $14 \%$ in 2002 to $28 \%$ in 2016 . The fraction with Medicaid was quite stable at 7 to $9 \%$ over this period. Part D coverage, introduced in 2006, grew to cover $18 \%$ of beneficiaries in 2016 .

The net result of all these shifts is that the fraction with no supplemental coverage declined from $16 \%$ in 2002 to only $5 \%$ in 2016 . However, taking into account the fact that Part $D$ covers only prescription drugs, the fraction with no supplemental coverage for doctor and hospital bills actually increased from $16 \%$ in 2002 to $23 \%$ in 2016. Therefore, it is unclear whether on average, Medicare beneficiaries' out-of-pocket spending risk has increased or decreased over this period.

Before proceeding to the out-of-spending risk analysis, note two facts about supplemental coverage: First, there is nonrandom selection into these different types of supplemental coverage. Table 2 shows average enrollee characteristics - age, fair/poor health, gender, poverty status, and education - by coverage type in 2016. Medicaid beneficiaries are, unsurprisingly, different from the other groups of beneficiaries, being significantly older, sicker, poorer, less well-educated, and more likely to be female than all other groups. Those with no supplemental coverage also tend to be poorer and sicker than individuals with coverage. These differences are a useful reminder that whether an individual has supplemental coverage, and if so what type they have, is the result of (constrained) choices by that individual. Therefore, in comparing out-of-pocket spending patterns across groups, it would be wrong to infer that coverage differences are responsible in a causal sense for any observed spending differences across respondent groups with different coverage types. For example, conditional on 
observable covariates such as self-reported health status, individuals who forego coverage may be (unobservably) healthier or less likely to use services to begin with, so that the observed spending difference between those with and without any supplemental coverage may understate the true impact of coverage on spending. (Note that the same argument applies to differences across groups in the dispersion of spending.)

Second, premium spending may differ significantly with coverage type. Table 3 shows average premiums overall; the fraction of enrollees who pay zero premium for supplemental coverage; and average, out-of-pocket, annual premium spending, conditional on having a nonzero premium, by supplemental coverage type. Unsurprisingly, Medicaid enrollees report paying almost no premiums, while nearly all Medigap enrollees (88\%) have to pay something for their coverage. Thirty-six percent of enrollees in employer plans and $42 \%$ of Medicare Advantage enrollees do not have to pay out-of-pocket for coverage. Among those who do pay for these types of coverage, those with employer coverage pay the most ( $\$ 3,322$ per year), followed closely by Medigap enrollees $(\$ 2,963)$. Beneficiaries' health spending risk is largely a function of out-of-pocket health care spending, rather than premiums, which are not uncertain ex ante in the way that out-of-pocket health care spending is. Therefore, the next set of results focuses on the distribution of health care spending without addressing premiums. I then present measures of the economic burden of households' spending, both with and without out-of-pocket premium spending. 


\section{Results, Part 2: Out-of-pocket health care spending; median and dispersion by insurance type}

Figure 2 shows trends over time in median out-of-pocket health care spending overall and by supplemental insurance type. Median spending overall is less than $\$ 1,000$ and declines slightly over time between 2002 and 2016. Looking at differences by supplemental insurance type, spending is lowest for beneficiaries with Medicaid coverage and highest for those with Medigap or Part $D$. These gradients by coverage type are largely stable over time, although spending for the group without any supplemental coverage drops in 2006 in a way consistent with the idea that beneficiaries with high out-of-pocket spending may have been more likely to enroll in Part D when it became available (Levy and Weir 2010). Zeroing in on one point in time, Figure 3 presents different moments of the out-of-pocket spending distribution by supplemental insurance status in 2016 . This figure shows that the spending distribution's $10^{\text {th }}$ percentile is zero for nearly all Medicare beneficiaries. As we move up the distribution, spending increases more slowly for those with Medicaid than for other beneficiaries, as we would expect, with spending for other groups increasing at a generally similar rate through approximately the $75^{\text {th }}$ percentile. At the distribution's highest points, those with no coverage and those with Medicaid report the highest outof-pocket spending. ${ }^{4}$

The fact that at the median, out-of-pocket spending is slightly higher for individuals with Medigap or Part $D$ than for those with no coverage at all reinforces the

\footnotetext{
${ }^{4}$ Further data quality analysis is needed to see whether the Medicaid result is spurious.
} 
importance of selection into coverage, as discussed above. In order to control for some observable elements of selection, such as demographic characteristics and selfreported measures of health, I estimate multivariate models of the form:

$$
O O P \text { spending }_{i j t}=b_{0}+b_{1} \cdot \text { insurance type }_{j}+b_{2} \cdot X_{i t}+Y E A R_{t}+e_{i j t}
$$

where insurance type is $_{j}$ a vector of supplemental insurance types. $X_{i t}$ is a vector of individual characteristics including age, gender, self-reported health status (excellent, very good, good, fair, poor), labor force status, years of education, number of activities of daily living for which the respondent has a limitation, number of instrumental activities of daily living for which the respondent has a limitation number, and number of chronic health conditions. YEARt is a vector of dummies for years 2002 through 2016. Model estimates use ordinary least squares with survey weights. For comparison, I also estimate a model without the vector of individual-level controls and the year dummies; that is, the model's only explanatory variables are the insurance type dummies, so this model simply estimates the differences in mean spending across groups defined by insurance type.

Table 4 reports the coefficients from both models: Column 1 reports the coefficients from the model without controls, while Column 2 reports coefficients from the model with controls. Focusing primarily on the model with controls, which addresses observable selection into coverage based on demographic and health characteristics, the estimates suggest that beneficiaries with Medicare Part D have out-of-pocket health care spending that is the same as those with no supplemental coverage, while those with Medicare Advantage and employer coverage have spending that is slightly lower than, but not significantly different from, the spending of those without supplemental 
coverage. Medigap enrollees have slightly higher out-of-pocket spending than those without supplemental coverage. Meanwhile, Medicaid beneficiaries have much lower mean spending than every other group. Thus, the multivariate linear regression models with simple covariates largely paint the same picture as the medians in Figure 2: At the middle of the distribution (median or mean), insurance - with the notable exception of Medicaid — may not be doing that much to reduce spending.

From an economic perspective, the point of insurance is to reduce risk associated with the realization of a random variable - in this case, out-of-pocket medical care spending. More simply put, insurance's real purpose is to rein in the top tail of the distribution. I will use two measures of the dispersion of observed spending (the realization of the random variable) as a proxy for risk: The standard deviation and the ratio of $90^{\text {th }}$ to $50^{\text {th }}$ percentile. The $90 / 50$ ratio, in particular, measures whether there is a long right tail on the distribution of out-of-pocket spending, which would suggest a lack of true insurance against costly events. Figure 4 presents the ratio of the $90^{\text {th }}$ percentile to the $50^{\text {th }}$ percentile of the out-of-pocket spending distribution, over time and by supplemental coverage type. This figure suggests that most types of supplemental coverage have a smaller $90 / 50$ ratio than no coverage, as one would expect. The exception is Medicaid although in this case, the quite high 90/50 ratio is driven largely by extremely low median spending in Medicaid. The standard deviation (Figure 5) is much noisier but appears to be higher, in recent years, for no coverage than for those with any supplemental coverage. 


\section{Results, Part 3: Health spending compared to household income}

Insurance may reduce risk in the economic sense, but we are also interested in the financial burden that average health spending represents compared to a household's income. Figures 6 and 7 present trends on the share of beneficiaries

whose out-of-pocket health care spending exceeds $10 \%$ of their household income. The estimates in Figure 6 do not include premium spending in out-of-pocket health care spending while those in Figure 7 do include premiums. Figure 6 shows that over time, around 20 to $25 \%$ of all Medicare beneficiaries 65 and older spend more than $10 \%$ of their household income on out-of-pocket medical care. Figure 7 is similar, but the outcome variable is total out-of-pocket health spending; that is, medical care plus health insurance premiums. On average, out-of-pocket premium spending for this group is about half as much as out-of-pocket medical care spending. Including premiums, more than a third of all beneficiaries 65 and older devote more than $10 \%$ of their income to out-of-pocket health spending. For Medigap enrollees, who pay the most in out-ofpocket premiums, just over one-half devote more than $10 \%$ of their income to out-ofpocket spending on health.

I also estimate multivariate models that use the same covariates as equation (1) above, but with a dependent variable equal to 1 if the individual has out-of-pocket spending greater than $10 \%$ of their household income. Out-of-pocket spending is measured both without premiums (that is: medical care spending only) and with premiums. For each of these outcomes, results are presented for a model with no controls and a model with the full set of demographic and health-related controls described above. These results are presented in Table 5. As before, the inclusion of 
these controls does surprisingly little to change the overall pattern of results. But the difference between the models for out-of-pocket spending on medical care versus those for out-of-pocket spending on medical care plus premiums (column 2 versus column 4) are striking. Compared to having no supplemental coverage, any kind of supplemental coverage - except Medicaid - reduces the risk of a high out-of-pocket spending burden for medical care while increasing the risk of a high out-of-pocket spending burden for medical care plus premiums (where "high" is defined as greater than $10 \%$ of household income). Medicaid uniformly reduces the risk of both types of spending burden. For all coverage types other than Medicaid, however, the tradeoff is fairly clear: Households are spending upfront on premiums in order to reduce bills later. (This is, after all, how insurance works.)

\section{Discussion}

This analysis shows that Medicare beneficiaries with supplemental insurance coverage generally face less risk of high out-of-pocket medical spending than those who have no such coverage. The tradeoff is that, except for those who have Medicaid, they also face higher premium payments. 


\section{References}

Cubanski, Juliette, Anthony Damico, Tricia Neuman, and Gretchen Jacobson. 2018. "Sources of Supplemental Coverage among Medicare Beneficiaries in 2016." Kaiser Family Foundation Data Note.

De Nardi, Mariacristina, Eric French, John Bailey Jones, and Jeremy McCauley. 2016. "Medical spending of the US elderly." Fiscal Studies 37(3-4): 717-747.

Goldman, Dana P., and Julie M. Zissimopoulos. 2003. "High out-of-pocket health care spending by the elderly." Health Affairs 22 (3): 194-202.

Gruber, Jonathan, and Helen Levy. 2009. "The evolution of medical spending risk." Journal of Economic Perspectives 23 (4): 25-48.

Levy, Helen, and David R. Weir. 2010. "Take-up of Medicare Part D: results from the Health and Retirement Study." Journals of Gerontology Series B: Psychological Sciences and Social Sciences 65, no. 4 (2010): 492-501.

Sonnega, Amanda, Jessica D. Faul, Mary Beth Ofstedal, Kenneth M. Langa, John WR Phillips, and David R. Weir. "Cohort profile: The Health and Retirement Study (HRS)." International Journal of Epidemiology 43, no. 2 (2014): 576-585. 
Table 1: Health and Retirement Study, 2002 - 2016; total sample size and size of the analytic sample for this study

\begin{tabular}{cccccc}
\hline & All HRS & Age>=65 & $\begin{array}{c}\text { Age>=65 and } \\
\text { has Medicare }\end{array}$ & $\begin{array}{c}\text { Analytic Sample } \\
\text { Age }=\mathbf{6 5} \text {, has Medicare, no } \\
\text { missing variables }\end{array}$ \\
\hline & Observations & Observations & Observations & Observations: & Households: \\
\hline $\mathbf{2 0 0 2}$ & 18,166 & 10,908 & 10,564 & 10,556 & 8,060 \\
$\mathbf{2 0 0 4}$ & 20,129 & 11,095 & 10,701 & 10,690 & 8,106 \\
$\mathbf{2 0 0 6}$ & 18,469 & 11,362 & 10,935 & 10,917 & 8,262 \\
$\mathbf{2 0 0 8}$ & 17,217 & 11,342 & 10,928 & 10,914 & 8,186 \\
$\mathbf{2 0 1 0}$ & 22,034 & 10,937 & 10,467 & 10,457 & 7,813 \\
$\mathbf{2 0 1 2}$ & 20,554 & 10,735 & 10,268 & 10,250 & 7,648 \\
$\mathbf{2 0 1 4}$ & 18,747 & 10,364 & 9,869 & 9,853 & 7,440 \\
$\mathbf{2 0 1 6}$ & 20,912 & 9,966 & 9,405 & 9,372 & 7,152 \\
\hline Total & 156,228 & 86,709 & 83,137 & $83,009^{*}$ & 13,547 \\
\hline
\end{tabular}

*These 83,009 observations represent data from 19,464 unique individuals across all years from 2002 through 2016. In a single given year (i.e., in the previous rows of the table), the number of observations and the number of unique individuals is the same. 
Table 2: Medicare beneficiaries 65 and older - characteristics by supplemental insurance type, Health and Retirement Study 2016

\begin{tabular}{lccccccccccccc}
\hline & \multicolumn{3}{c}{ Age } & \multicolumn{3}{c}{$\begin{array}{c}\text { Fair/poor } \\
\text { health }\end{array}$} & \multicolumn{3}{c}{ Female } & \multicolumn{2}{c}{$\begin{array}{c}\text { Income } \\
\text { <Poverty }\end{array}$} & \multicolumn{2}{c}{$\begin{array}{c}\text { Education } \\
<\text { HS }\end{array}$} \\
\hline & Mean & SE & Mean & SE & Mean & SE & Mean & SE & Mean & SE \\
\hline None & 75.8 & 0.3 & 0.342 & 0.019 & 0.508 & 0.022 & 0.148 & 0.011 & 0.315 & 0.021 \\
Part D only & 75.1 & 0.2 & 0.328 & 0.011 & 0.543 & 0.012 & 0.054 & 0.006 & 0.332 & 0.011 \\
Medicare & & & & & & & & & & \\
Advantage & 74.8 & 0.2 & 0.249 & 0.009 & 0.569 & 0.010 & 0.051 & 0.005 & 0.345 & 0.009 \\
$\begin{array}{l}\text { Medigap } \\
\text { Employer }\end{array}$ & 74.1 & 0.2 & 0.231 & 0.012 & 0.600 & 0.014 & 0.027 & 0.007 & 0.344 & 0.013 \\
coverage & 74.0 & 0.2 & 0.204 & 0.009 & 0.542 & 0.010 & 0.026 & 0.005 & 0.271 & 0.010 \\
Medicaid & 76.2 & 0.3 & 0.544 & .015 & .632 & .017 & .348 & .009 & .273 & 0.016 \\
\hline
\end{tabular}


Table 3: Medicare beneficiaries 65 and older - out-of-pocket premiums for supplemental coverage, Health and Retirement Study 2016

\begin{tabular}{llll}
\hline & $\begin{array}{l}\text { Average } \\
\text { premium } \\
\text { spending } \\
\text { (including } \\
\text { zeroes) }\end{array}$ & $\begin{array}{l}\text { Fraction with } \\
\text { zero premium }\end{array}$ & $\begin{array}{l}\text { Average } \\
\text { premium } \\
\text { spending if }>\mathbf{0}\end{array}$ \\
\hline None & $\$ 55$ & 0.979 & $\$ 2,615$ \\
Part D only & 764 & 0.590 & 1,865 \\
Medicare & & 0.419 & 1,396 \\
Advantage & 810 & 0.116 & 2,963 \\
Medigap & 2,621 & 0.355 & 3,322 \\
Employer coverage & 2,144 & 0.748 & 1,638 \\
Medicaid & 412 & 0.450 & 2,401 \\
\hline Total & 1,321 & & \\
\hline
\end{tabular}

Note: Real 2016 dollars 
Table 4: Medicare beneficiaries 65 and older - out-of-pocket medical care spending, multivariable linear models, Health and Retirement Study 2016

\begin{tabular}{|c|c|c|}
\hline Controls included? & (1) & $\begin{array}{l}\text { (2) } \\
\text { Yes }\end{array}$ \\
\hline \multicolumn{3}{|l|}{ Explanatory variables: } \\
\hline None & \multicolumn{2}{|c|}{ Omitted category } \\
\hline Part D only & $\begin{array}{l}-186 \\
(98)\end{array}$ & $\begin{array}{l}0 \\
(100)\end{array}$ \\
\hline Medicare Advantage & $\begin{array}{l}-350^{* * *} \\
(90)\end{array}$ & $\begin{array}{l}-133 \\
(91)\end{array}$ \\
\hline Medigap & $\begin{array}{l}128 \\
(94)\end{array}$ & $\begin{array}{l}185^{*} \\
(94)\end{array}$ \\
\hline Employer & $\begin{array}{l}-203^{*} \\
(85)\end{array}$ & $\begin{array}{l}-143 \\
(85)\end{array}$ \\
\hline Medicaid & $\begin{array}{l}-1,084^{* \star *} \\
(109)\end{array}$ & $\begin{array}{l}-1,412^{\star \star \star} \\
(112)\end{array}$ \\
\hline Constant & $\begin{array}{l}2,214^{\star * *} \\
(76)\end{array}$ & $\begin{array}{l}46 \\
(319)\end{array}$ \\
\hline $\begin{array}{l}\text { Mean of dependent } \\
\text { variable }\end{array}$ & $\$ 1,982$ & $\$ 1,982$ \\
\hline Unweighted sample size & 80,151 & 80,136 \\
\hline $\begin{array}{l}\text { Notes: Standard errors in } p \\
p<0.001 ; \text { In column } 2 \text {, mod } \\
\text { reported health and disabili } \\
\text { (see text for more details). }\end{array}$ & $\begin{array}{l}\text { ntheses. * } \\
\text { cludes cor } \\
\text { abor force }\end{array}$ & $\begin{array}{l}0.01 ;{ }^{* * *} \\
\text { gender, self- } \\
\text { ation, and year }\end{array}$ \\
\hline
\end{tabular}


Table 5: Medicare beneficiaries 65 and older - is out-of-pocket spending on medical care/health greater than $10 \%$ of income? Multivariable linear models, Health and Retirement Study 2016

\begin{tabular}{|c|c|c|c|c|}
\hline \multirow{3}{*}{$\begin{array}{l}\text { Outcome variable: } \\
\text { Controls included? } \\
\text { Explanatory variables: }\end{array}$} & \multicolumn{2}{|c|}{$\begin{array}{l}\text { Out-of-pocket medical } \\
\text { spending } \\
\text { (no premiums) }\end{array}$} & \multicolumn{2}{|c|}{$\begin{array}{l}\text { Out-of-pocket health spending } \\
\text { (includes premiums) }\end{array}$} \\
\hline & No & Yes & No & Yes \\
\hline & & & & \\
\hline None & \multicolumn{4}{|c|}{ Omitted category } \\
\hline \multirow[t]{2}{*}{ Part D only } & $-0.043^{* * *}$ & $-0.017^{* *}$ & $0.042^{* * *}$ & $0.061^{* * *}$ \\
\hline & $(0.006)$ & $(0.006)$ & $(0.007)$ & $(0.007)$ \\
\hline \multirow[t]{2}{*}{ Medicare Advantage } & $-0.055^{\star * *}$ & $-0.023^{* * *}$ & $0.028^{* * *}$ & $0.054^{* * *}$ \\
\hline & $(0.006)$ & $(0.006)$ & $(0.007)$ & $(0.007)$ \\
\hline \multirow[t]{2}{*}{ Medigap } & $-0.028^{* \star *}$ & -0.008 & $0.297^{* * *}$ & $0.313^{* * *}$ \\
\hline & $(0.006)$ & $(0.006)$ & $(0.007)$ & $(0.007)$ \\
\hline \multirow[t]{2}{*}{ Employer } & $-0.093^{* * *}$ & $-0.059^{* * *}$ & $0.098^{* * *}$ & $0.136^{* * *}$ \\
\hline & $(0.006)$ & $(0.005)$ & $(0.006)$ & $(0.006)$ \\
\hline \multirow[t]{2}{*}{ Medicaid } & $-0.112^{\star \star *}$ & $-0.172^{\star \star \star}$ & $-0.097^{* * *}$ & $-0.158^{\star \star *}$ \\
\hline & $(0.007)$ & $(0.007)$ & $(0.008)$ & $(0.008)$ \\
\hline \multirow[t]{2}{*}{ Constant } & $0.280^{* * *}$ & $0.115^{* * *}$ & $0.325^{* * *}$ & 0.001 \\
\hline & $(0.005)$ & $(0.020)$ & $(0.006)$ & $(0.024)$ \\
\hline $\begin{array}{l}\text { Unweighted sample } \\
\text { size }\end{array}$ & 80,151 & 80,136 & 80,151 & 80,136 \\
\hline
\end{tabular}

Notes: Standard errors in parentheses. ${ }^{*} p<0.05,{ }^{* *} p<0.01,{ }^{* * *} p<0.001$. In columns 2 and 4 , model includes controls for age, gender, self-reported health and disability, labor force status, education, and year (see text for more details). 
Figure 1: Supplemental insurance coverage of Medicare beneficiaries ages 65+

Health and Retirement Study, 2002 - 2016

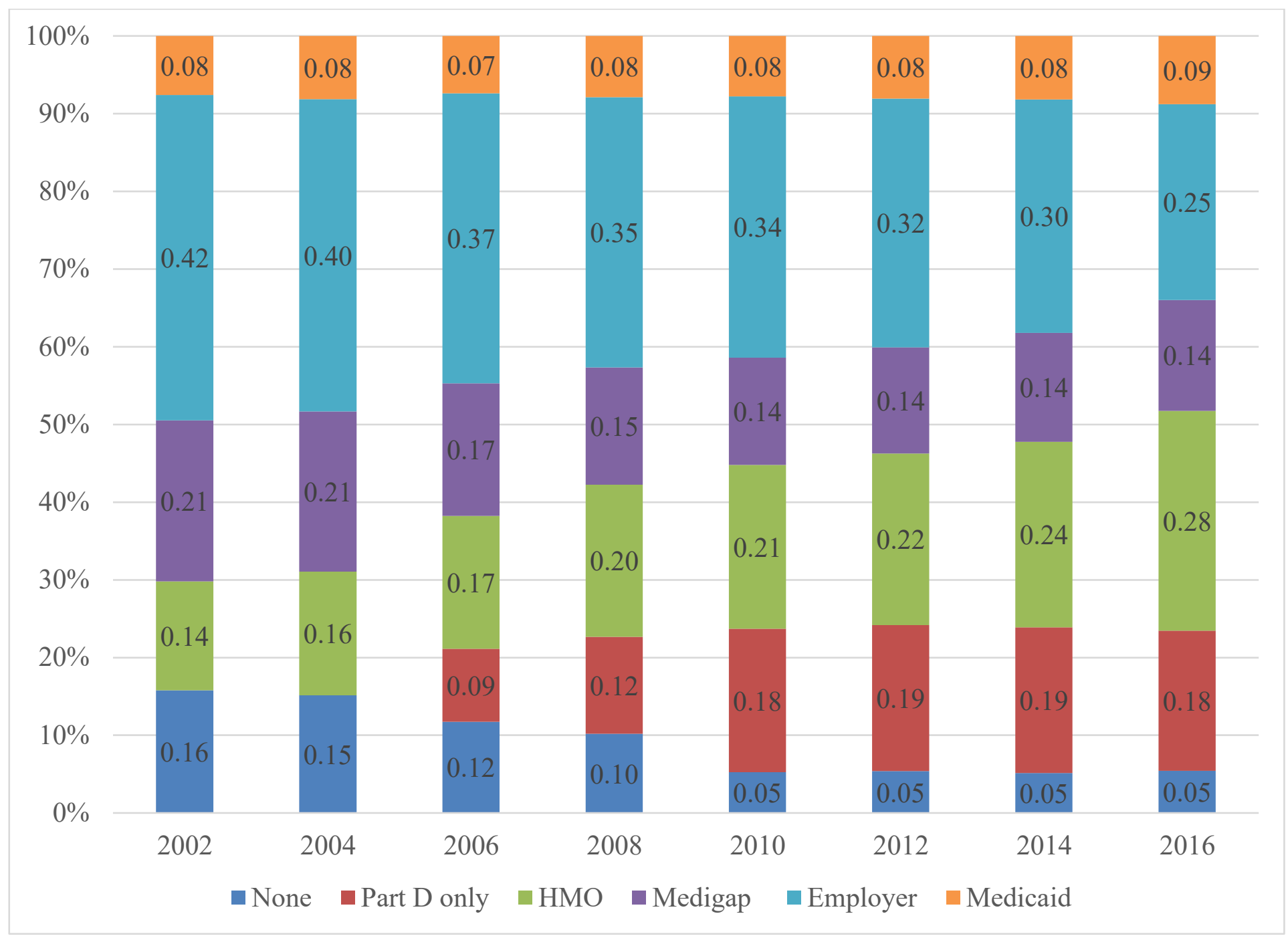


Figure 2: Median out-of-pocket health care spending (1 year, respondent-level) Medicare beneficiaries ages 65+ by supplemental insurance status, Health and Retirement Study, 2002 - 2016

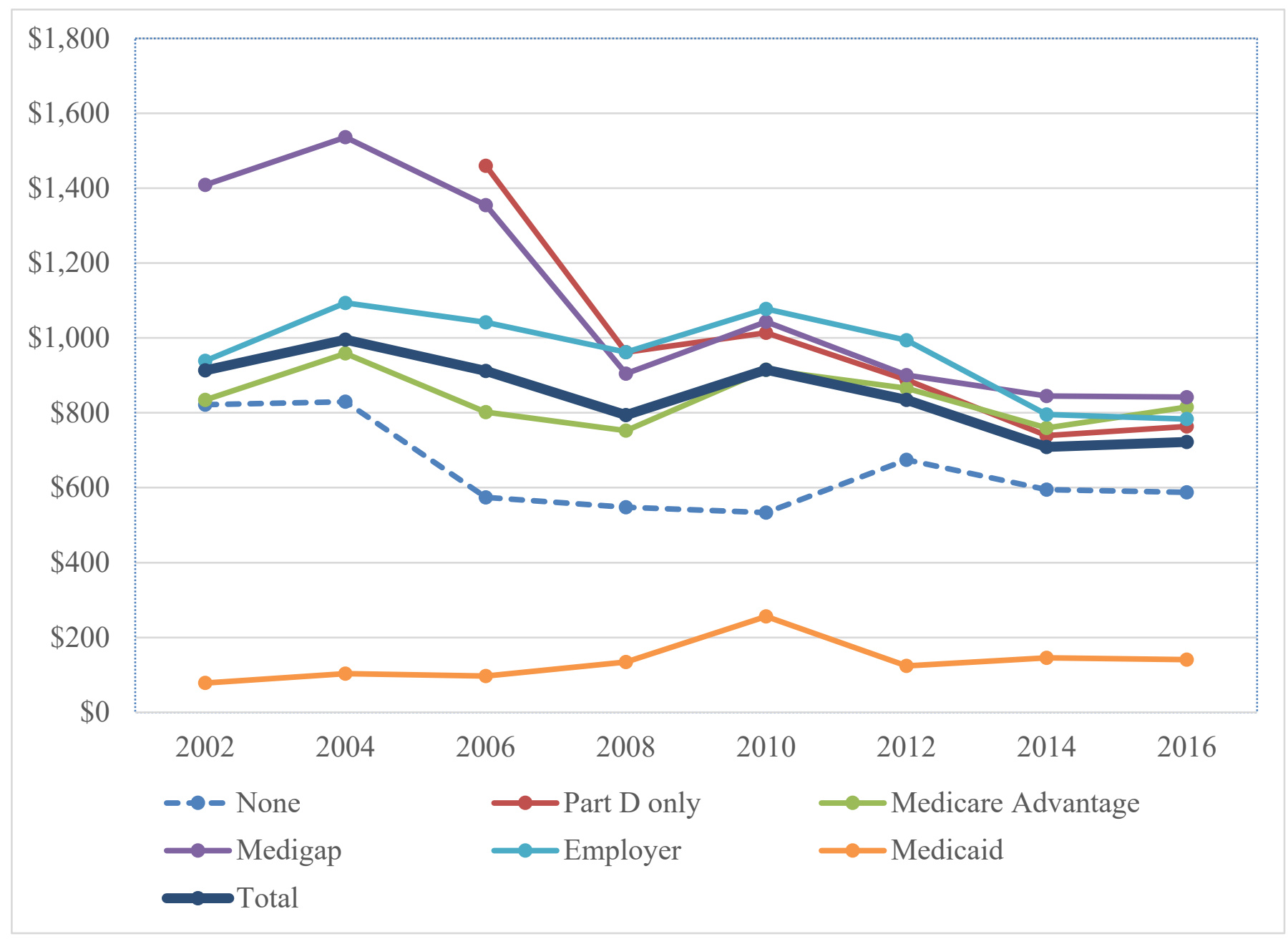


Figure 3: Percentiles of out-of-pocket health care spending Medicare beneficiaries ages 65+ by supplemental insurance status Health and Retirement Study, 2016

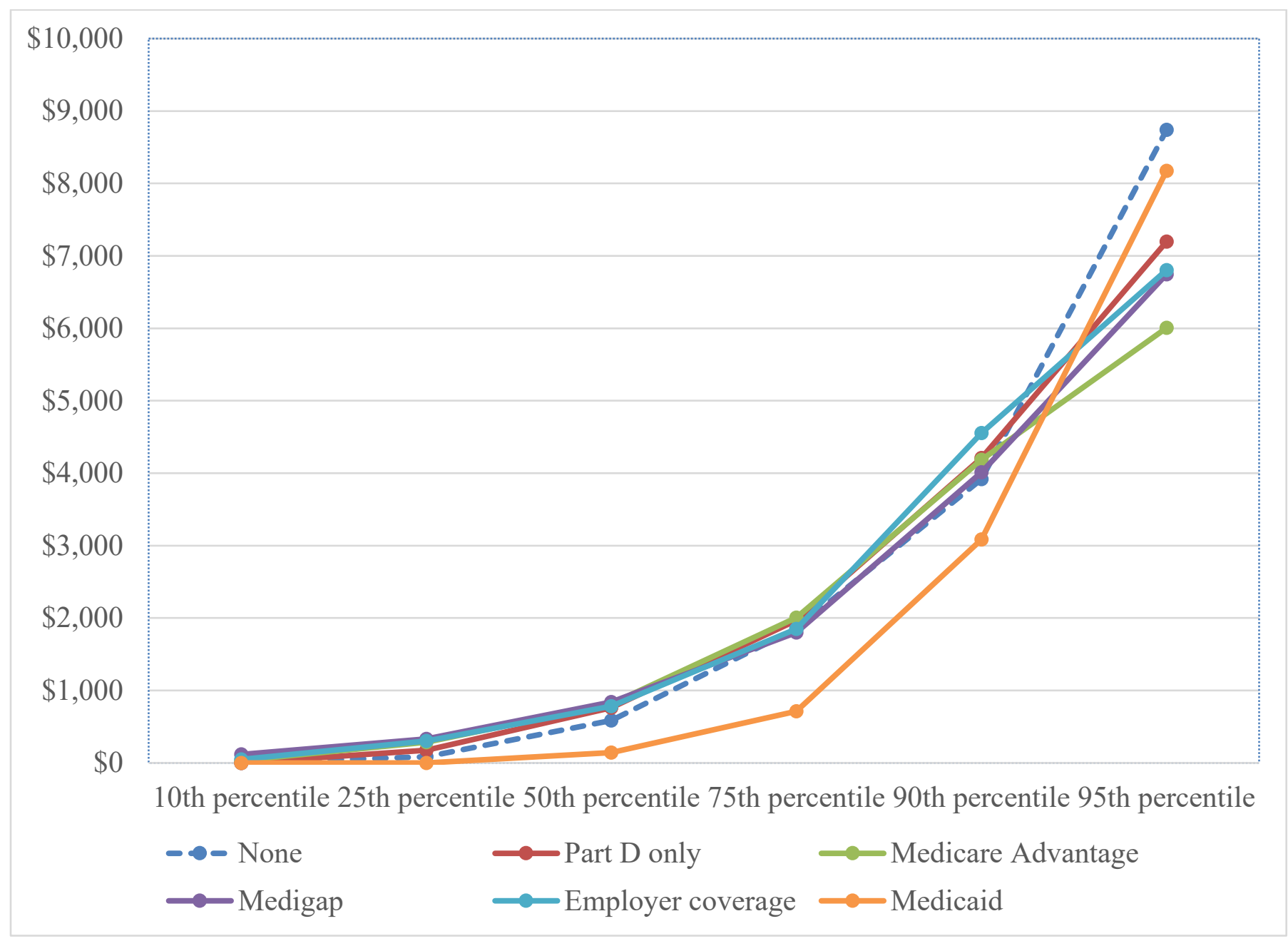


Figure 4: Ratio of 90 th to 50th percentile out-of-pocket health care spending (1 year, respondent-level) Medicare beneficiaries ages 65+ by supplemental insurance status, Health and Retirement Study, 2002 - 2016

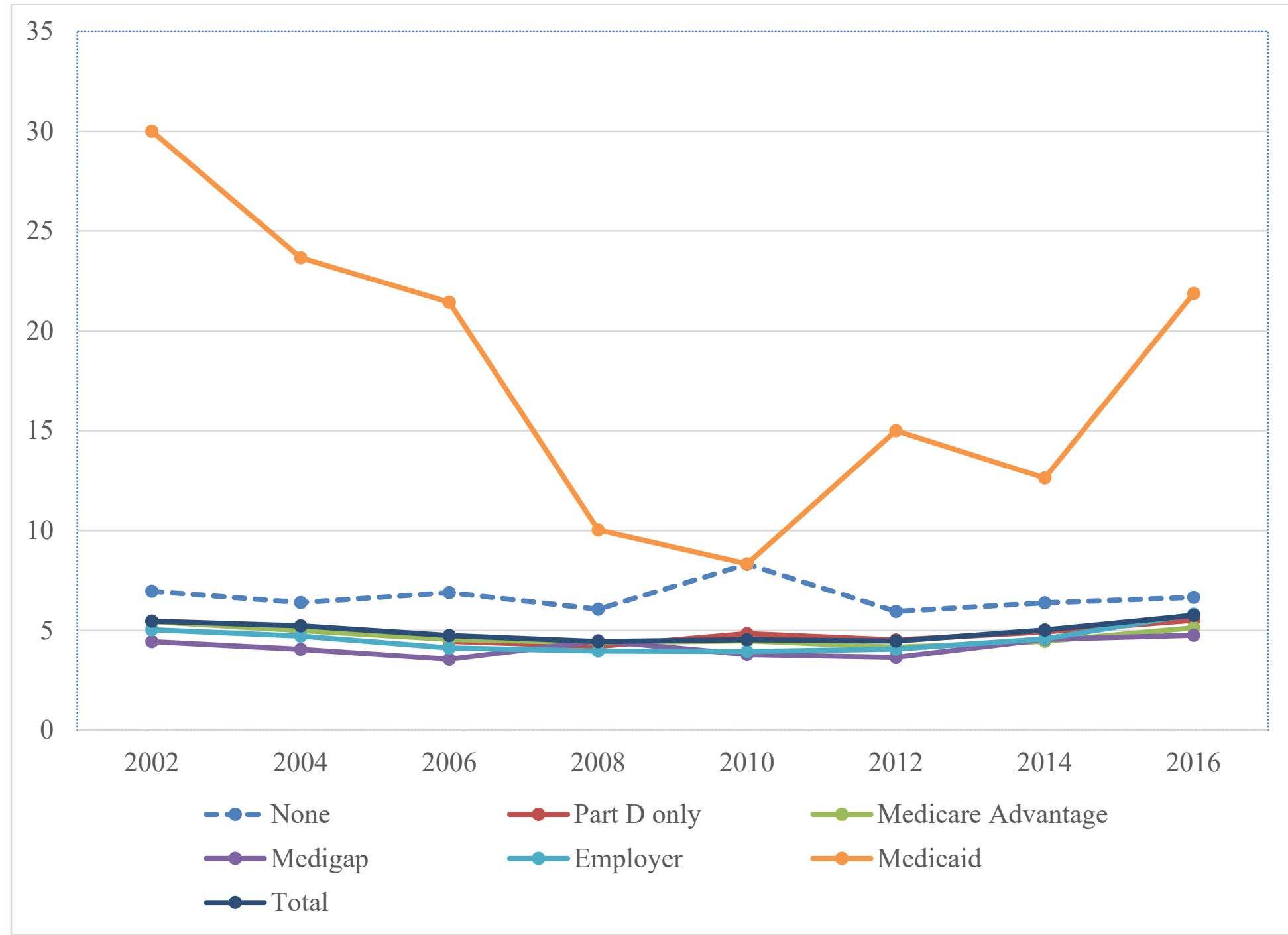


Figure 5: Standard deviation of out-of-pocket health care spending (1 year, respondent-level) Medicare beneficiaries ages 65+ by supplemental insurance status, Health and Retirement Study, 2002 - 2016

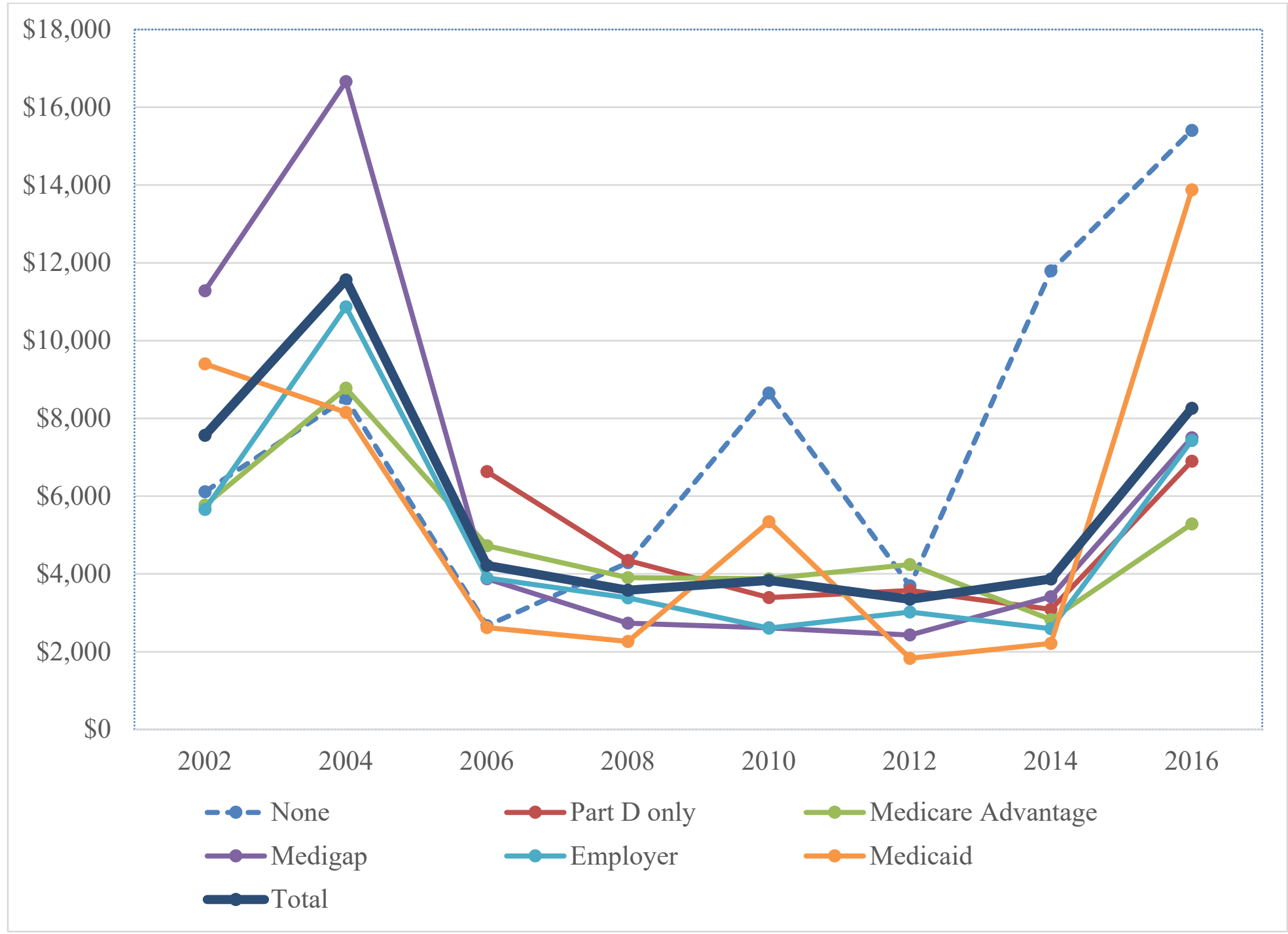


Figure 6: Share with out-of-pocket medical care spending (not including premiums) > $10 \%$ of income Medicare beneficiaries ages 65+ by supplemental insurance status, Health and Retirement Study, 2002 - 2016

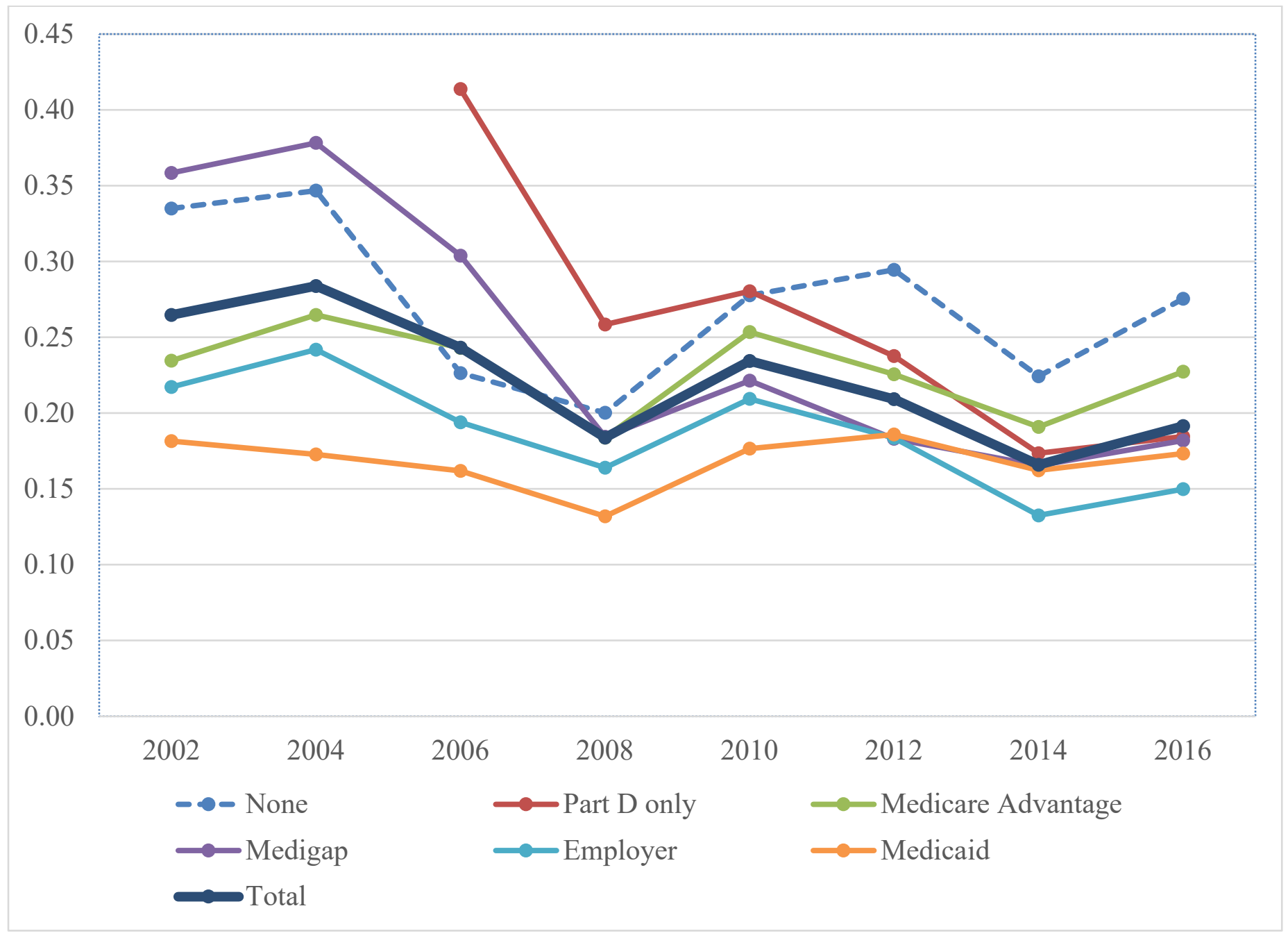


Figure 7: Share with out-of-pocket health spending (including premiums) $>10 \%$ of income Medicare beneficiaries ages 65+ by supplemental insurance status, Health and Retirement Study, $2002-2016$

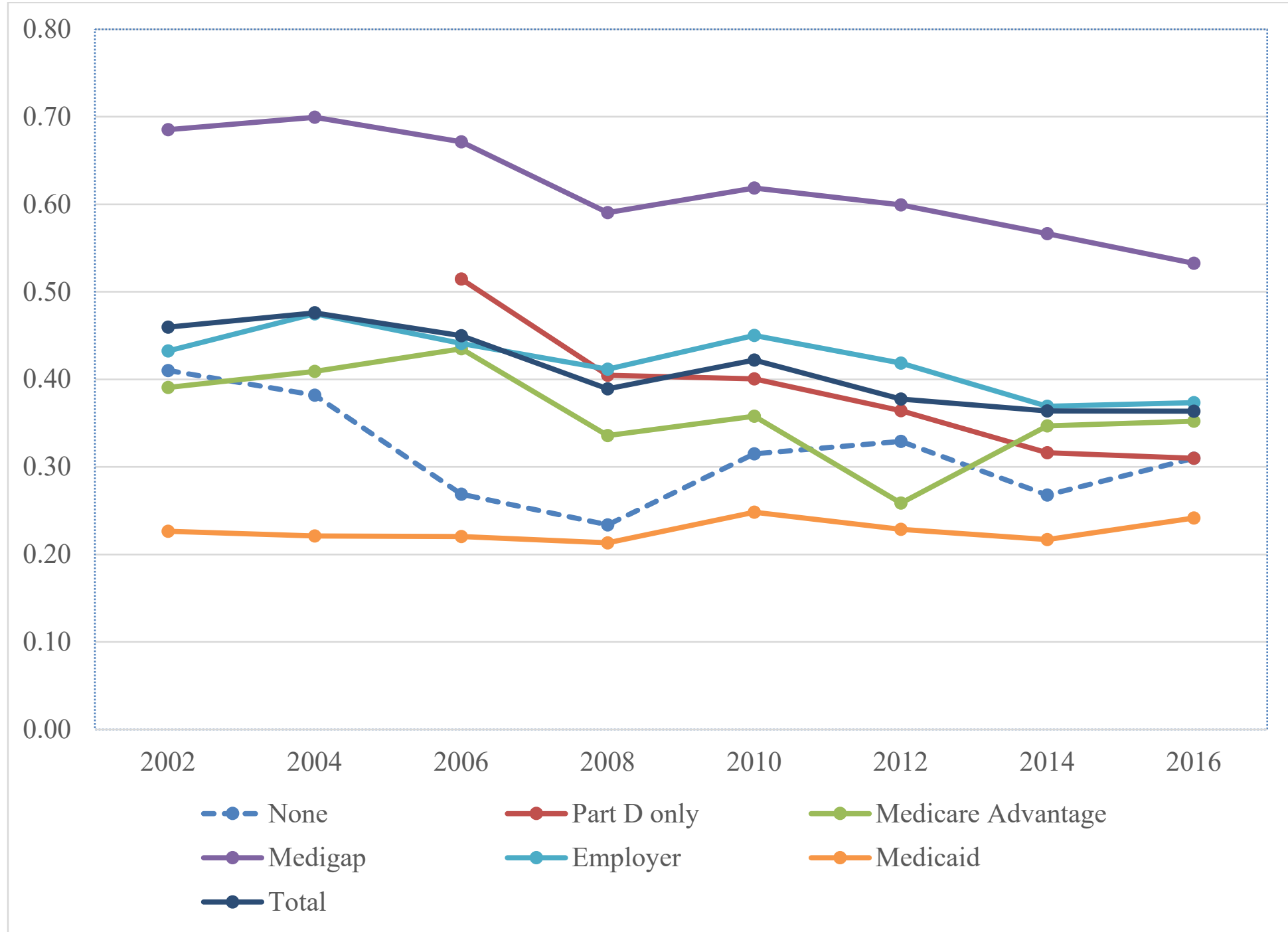

